\title{
EDITORIAL
}

\section{ARMY MEDICAL STATISTICS}

Recent correspondence in both this Journal and the Lancet has called attention to the need for reliable statistics in the particular context of military perinatal mortality rates. The subject of the perinatal mortality experienced by Army families in general and by Gurkha families in particular is ably presented by Brigadier Worsley, the Director of Army Preventive Medicine, in the correspondence columns of this issue ( $p$ 55); little more remains to be said except to ensure that all readers are correctly informed of what is measured by the rate in question and what is its special significance as an indicator of health care delivery. The perinatal mortality rate, a fairly recent addition to the armamentarium of vital statistics, is defined as:

Perinatal mortality rate $=\frac{\begin{array}{c}\text { Number of stillbirths and deaths in the } \\ \text { first week of life }\end{array}}{\text { Total number of births (both live and still) }} \times 1000$

The rate is employed extensively to assess the effectiveness of the obstetrical services in the wider sense and it has long been known that there is a positive association between high rates and low socio-economic status. The national rates (for England and Wales) have shown a progressive reduction since 1975 and the official figure for 1979 was 14.6 per thousand total births ${ }^{1}$. Despite these substantial recent reductions in the rate, comparison with 32 other developed countries reveals little ground for complacency. England and Wales come into the lower half, 19th out of 32. Direct comparison between countries is not an entirely valid exercise unless cognisance is taken of the relatively high frequency in UK of lower birthweight babies and congenital malformations. These particular factors have been inadequately evaluated in the correspondence on Gurkha and Army perinatal mortality rates and for this reason the controversy in the pages of this Journal and the Lancet has lacked conviction. In this arena there is need for obstetricians and paediatricians to learn more of the necessary epidemiological skills.

Well over a hundred years ago Florence Nightingale was writing about the need for accurate medical statistics and it seems that much of her pleading, teaching and writing has fallen on less than fertile ground. There is no doubt that the Army has developed an excellent and comprehensive, if somewhat cumbersome system of medical statistics but it can do no better than collect, collate and analyse the information derived from the data sources. Often this information is less accurate and reliable than it should be, and particularly so in relation to morbidity rates and prevalence - cogently if briefly demonstrated by Lt Col R H Hardie in his paper "Morbidity Records, Need or Nuisance"

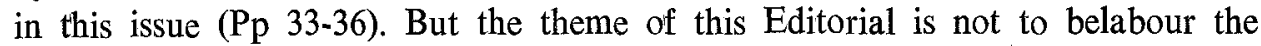
medical statistical system because in general it is fundamentally good - and 
certainly the envy of many civil health authorities. The present purpose is to encourage a two-fold commitment to medical statistical matters. First an increased concern among all members of the Army Medical Services for the accuracy of statistical information at its point of compilation. Second, as exemplified by the arguments over Gurkha perinatal mortality and care, is the need for a much greater awareness, knowledge and understanding of the usefulness and limitations of statistical methodology. It has been truly said that a little learning is a dangerous thing and nowhere is this more true than in the field of medical statistics and epidemiology. There is a strong case for including military epidemiology as a mandatory subject in the postgraduate curriculum for all RAMC doctors.

\section{REFERENCE}

1. Department of Health and Social Security. On the state of the public health for the year 1979. London: HMSO, 1980.

\section{Appointments to The Queen}

The following appointments have been made:-

Col A D Bremner, TD, RAMC(V), CO, 205 General Hospital, RAMC(V), to be Honorary Surgeon to The Queen.

Col W M Elder, TD, RAMC(V), CO, 207 General Hospital, RAMC(V), to be Honorary Physician to The Queen.

\section{Colonel Commandant RAMC}

Maj Gen R N Evans, CB, MB, ChB, FFARCS, DTM\&H, was appointed Colonel Commandant Royal Army Medical Corps on 26 November 1981, in succession to Maj Gen R J Gray, CB, MB, BS, FFCM, tenure expired. 